\title{
SISTEM PENILAIAN PENGUJI PADA PESSTA+ S2 BERBASIS YII FRAMEWORK SEBAGAI MEDIA PENGINPUTAN NILAI SIDANG TESIS DI PERGURUAN TINGGI
}

\author{
Indri Handayani ${ }^{1}$ \\ Yulianto $^{2}$ \\ Fina Andhara Khumaida ${ }^{3}$ \\ Dosen STMIK Raharja ${ }^{1}$ \\ STMIK Raharja Jurusan Sistem Informasi ${ }^{2,3}$ \\ Jl. Jendral Sudirman No. 40, Modernland, Tangerang ${ }^{1,2,3}$ \\ E-mail: indri@raharja.info, ${ }^{1}$ yulianto@raharja.info ${ }^{2}$, andhara@raharja.info ${ }^{3}$
}

\begin{abstract}
ABSTRAK
Pengembangan sistem merupakan suatu upaya untuk meningkatkan kualitas sistem agar lebih berinovasi. Perguruan Tinggi Raharja merupakan salah satu perguruan tinggi ilmu komputer yang memiliki banyak sistem dalam mendukung kegiatan akademiknya. Pada Perguruan Tinggi Raharja terdapat sistem PESSTA+ (Penilaian Sidang Thesis Akhir Plus) yang memberikan kemudahan bagi mahasiswa sebagai media untuk memenuhi poin penilaian sidang Thesis. Penilaian Penguji sangatlah penting untuk memudahkan penguji dalam memberikan penilaian yang ditujukan kepada mahasiswa Thesis. Namun, pada sistem penilaian penguji saat ini memiliki permasalahan yaitu masih konvensional yang dimana penguji mengisi penilaian secara tertulis belum diterapkan secara online.Dari permasalahan tersebut maka perlu adanya pengembangan pada penilaian penguji agar dapat diakses secara online pada sistem PESSTA+ sehingga menjadi lebih sistematis, terorganisir, efektif dan efisien dan dapat diakses secara online. Pada pengembangan sistem penilaian Penguji ini menggunakan salah satu Framework PHP yaitu Yii Framework.
\end{abstract}

Kata kunci : PESSTA+, Penilaian Penguji, Thesis

\begin{abstract}
System development is an effort to improve the quality of the system to be more innovative. Raharja University is one of the computer science colleges that has many systems in supporting academic activities. At Raharja University there is a PESSTA + system (Assessment of Thesis Plus Assembly) which provides convenience for students as a medium to meet the assessment points of Thesis trial. Assessment of Examiners is very important to facilitate testers in providing assessments addressed to Thesis students. However, the current assessment system has problems that still use semi-manual system that can only be accessed on campus and not efficient. From these problems it is necessary to develop the assessment of testers to be accessible on the PESSTA + system so that it becomes more systematic, organized, accessible anywhere online. In the development of a scoring system this Tester uses one of the PHP Frameworks namely Yii Framework.
\end{abstract}

Keywords: PESSTA +, Assessment of counselors, Thesis 


\section{PENDAHULUAN}

Sidang Tesis adalah proses presentasi penulisan dan penelitian yang dianggap siap dan selesai, mahasiswa mempresentasikan hasil karya ilmiahnya tersebut pada Dosen Penguji . Pengertian Penilaian merupakan proses pengumpulan dan pengolahan suatu informasi yang bermakna dalam mengambil keputusan dan menentukan kualitas peserta didik . Penilaian juga dapat sebagai acuan untuk memperoleh informasi tentang peserta didik seberapa baik hasil belajar maupun yang sudah di capai oleh peserta didik. Hasil penilaian dapat berupa nilai kuantitatif (angka) dan nilai kualitatif (pernyataan naratif dalam kata-kata). Penilaian adalah sikap dan persepsi positif terhadap pengetahuan, pemerolehan dan pengintegrasian pengetahuan, perluasan dan pendalaman pengetahuan, penggunaan pengetahuan secara bermakna, dan kebiasaan berfikir produktif (I Wayan Suastra 305-2016) .

Mutu dan pengetahuan dunia pendidikan beserta elemennya saat ini tentunya semua tidak terlepas dari penggunaan teknologi komputer sebagai salah satu media yang banyak memberikan manfaat. Teknologi pun kini bukan hanya menjangkau perkantoran tetapi jangan instansi-instansi masyarakat seperti Perguruan Tinggi. Akan tetapi pemenuhan kebutuhan terhadap informasi pada saat ini tidak lepas dari pemakaian dan pemanfaatan komputer dengan semaksimal mungkin. Dibandingkan dengan tidak adanya teknologi, kekurangannya pemahaman terhadap teknologi komputer menghambat akses atau jalannya suatu instansi akademis ke dunia luar.

Saat ini pada Perguruan Tinggi Raharja masih menggunakan sistem penilaian penguji pascasarjana yang masih semi manual dimana setelah penguji memberikan hasil penilaian sidang, selanjutnya sekertaris jurusan menginput nilai ke dalam excel.

Namun pada sistem yang berjalan saat ini, terdapat beberapa kekurangan dimana sistem penilaian sidang mahasiswa pascasarjana masih konvensional dan saat ini ingin diterapkan untuk bisa di akses secara online. Sistem penilaian sidang pascasarjana saat ini masih menginput secara manual menggunakan excel.

Dengan permasalahan tersebut, diperlukan sebuah sistem yaitu Penilaian Sidang Thesis Akhir yang dapat di akses secara online serta dapat di akses pada sistem PESSTA+ . Tujuan dibuatnya sistem penilaian sidang thesis akhir plus pascasarjana S2 pasa PESSTA+ adalah mengoptimalkan penilaian sidang, menghemat waktu dan untuk mempermudah penguji sidang agar lebih efektif dan efisien.

PESSTA+ adalah sebuah sistem informasi penilaian sidang tesis akhir plus pada Perguruan Tinggi Raharja, merupakan suatu sistem validasi penilaian Objektif Sidang yang dapat di akses secara mandiri dan online, sehingga Mahasiswa dapat melakukan submit di mana saja dan kapan saja. Yang ditujukan untuk mempermudah mahasiswa dalam memenuhi 10 point Penilaian Objektif pada saat Sidang Tesis.

Penelitian ini dilakukan untuk meningkatkan kualitas serta mutu dan menganalisa kendala-kendala apa saja yang ada pada sistem Penilaian Penguji sidang yang sedang berjalan saat ini dan melakukan pembuatan sistem yang memudahkan penguji sidang dalam memberikan penilaian.

\section{LITERATURE REVIEW}

Pengumpulan informasi sangat dibutuhkan dalam menggali referensi-referensi yang berkaitan sesuai dengan penelitian yang dilakukan. Adanya studi pustaka (literature review) ini 
untuk mengidentifikasi kesenjangan, meneruskan penelitian yang sudah dilakukan sebelumnya dan menghindari pembuatan ulang. Menurut Mahfud (2016 : 15), "Tinjauan pustaka adalah sebagai penelusuran terhadap literature yang telah ada sebelumnya dan berkaitan dengan penelitian ini". Berikut ini ada referensi studi pustaka (literature review), diantaranya yaitu:

1. Penelitian dilakukan oleh Indri Handayani, dkk.(2016), yang berjudul "Penerapan Sistem Validasi Jurnal Di Pessta+ Sebagai Penilaian Artikel Ilmiah dalam Mendukung Kegiatan Civitas Akademika" Penelitian ini mengulas tentang PESSTA (Penilaian Sidang Skripsi dan Tugas Akhir) adalah sebuah sistem pelayanan kampus yang ditujukan bagi dewan penguji dalam menyusun alur pelaksanaan sidang. Hasil akhir penelitian ini adalah menggunakan sebuah sistem baru yang bernama PESSTA+ (Penilaian Sidang Skripsi dan Tugas Akhir Plus) yang saat ini sedang dalam tahap pembuatan. Dengan adanya sistem ini diharapkan mahasiswa dapat dengan mudah melakukan validasi jurnal dan mendapatkan nilai yang valid sebagai salah satu syarat kelulusan pada Perguruan Tinggi Raharja.

2. Penelitian dilakukan oleh Egi Wijatriana, dkk. (2018), yang berjudul "Penerapan Sistem Validasi Jurnal Di PESSTA+ Sebagai Penilaian Artikel Ilmiah Dalam Mendukung Kegiatan Civitas Akademik" Penelitian ini mengulas tentang Website PESSTA+ merupakan sistem validasi Penilaian Objektif Sidang yang dapat di akses secara mandiri dan online. Dan tidak hanya itu pengguna Stat Counter pun dapat membantu pengelola dalam hal memonitoring aktivitas website secara detail karena pada dasarnya Stat Counter juga menampilkan data dan informasi mengenai aktivitas setiap pengunjung secara rinci.

3. Penelitian dilakukan oleh Erick Febriyanto, dkk. (2018), yang berjudul "Penerapan Viewboard Sebagai Media Informasi Sidang Skripsi Pada PESSTA+ di Perguruan Tinggi" Penerapan ini mengulas tentang PESSTA + (Penilaian Sidang Skripsi dan Tugas Akhir Plus) sebagai media validasi jurnal dan hibah yang dilakukan oleh mahasiswa secara online dan mandiri diharapkan dapat memberikan informasi yang berkualitas dan dapat dipercaya, oleh karena itu, dibutuhkan sarana untuk memberikan solusi, mengevaluasi proses dan memonitoring kinerja proses yang sedang berjalan. Dengan merancang sebuah Viewboard, diharapkan dapat memberikan gambaran informasi mengenai kegiatan sidang skripsi / tugas akhir dari PESSTA +.

4. Penelitian ini dilakukan oleh Mohamad Farozi, dkk. (2015), yang berjudul "Perancangan Sistem Informasi Penilaian Kinerja Sumber Daya Manusia Menggunakan Metode Gamifikasi" penilaian ini mengulas tentang Rancangan sistem informasi penilaian kinerja SDM dengan metode gamifikasi ditampilkan melalui website dan memungkinkan challenge (tugas dan tanggung jawab). Metode gamifikasi yang digunakan mengacu pada proses untuk memperkenalkan, mengubah dan mengoperasikan sistem pelayanan serta interaksi antara manusia dan komputer yang banyak mengambil inspirasi dari mechanic game yang membuat proses bisnis lebih menyenangkan dengan memasukkan unsur-unsur permainan didalamnya serta memastikan produktivitas dan semangat kerja karyawan.

5. Penelitian ini dilakukan oleh Saefudin, dkk. (2015), yang berjudul "Sistem Pendukung Keputusan Untuk Penilaian Kinerja Karyawan PT. Mulya Spindo Mills Menggunakan Metode Algoritma C4.5" penelitian ini mengulas tentang Sistem Pendukung Keputusan Untuk Penilaian Kinerja Karyawan Menggunakan Metode Algoritma C4.5 merupakan suatu sistem yang dibangun untuk dapat membantu pihak perusahaan dalam menentukan kinerja karyawan sesuai kriteria. Tujuan dari penelitian ini adalah terbangunnya sistem Pendukung Keputusan Untuk Penilaian Kinerja Karyawan Menggunakan Metode Algoritma C4.5 dengan kriteria-kriteria yang telah ditentukan oleh perusahaan. 
6. Penelitian ini dilakukan oleh Desi Ratna Sari, dkk. (2018), yang berjudul "Sistem Pendukung Keputusan untuk Rekomendasi Kelulusan SidangSkripsi Menggunakan Metode AHP-TOPSIS" Penelitian ini mengusulkan sebuah sistem pendukung keputusan untuk menentukan kelulusan Sidang skripsi menggunakan metode AHP dan TOPSIS. Metode AHP melakukan pembobotan kriteria untuk menghasilkan nilai pada setiap kriteria, dimana hasil nilai dari setiap kriteria digunakan untuk mendapatkan suatu peringkat dari beberapa alternatif dengan TOPSIS.

7. Penelitian ini dilakukan oleh Nadya Prabaningrum. (2018), yang berjudul "SISTEM INFORMASI SIDANG TUGAS AKHIR DAN PENDAFTARAN YUDISIUM BERBASIS WEB PROGRAM STUDI KOMSI SV UGM" Penelitian ini mengusulkan penilaian sidang yang masih dilakukan secara manual di atas kertas dan tidak saling terintegrasi antar anggota sidang. Berdasarkan permasalahan tersebut, perlu adanya pembangunan Sistem Informasi Sidang Tugas Akhir dan Pendaftaran Yudisium. Sistem ini bertujuan untuk memudahkan pengelolaan pemberkasan, data penilaian tugas akhir pada tahap sidang hingga pendaftaran yudisium, dan mengurangi penggunaan kertas berlebih. Tujuan dari pengembangan sistem informasi tersebut yaitu untuk membuat lebih efisien dalam pengelolaan pemberkasan, data penilaian tugas akhir pada tahap sidang hingga pendaftaran yudisium.

8. Penelitian ini dilakukan oleh Mokhamad Ramdhani Raharjo. (2018), yang berjudul "SISTEM PENDUKUNG KEPUTUSAN KELULUSAN UJIAN AKHIR DENGAN METODE GAP/PROFILE MATCHING PADA FAKULTAS TEKNOLOGI INFORMASI UNISKA MAAB" Penelitian ini membahas tentang Ujian akhir merupakan ujian yang harus ditempuh oleh mahasiswa atau mahasiswi setelah menyelesaikan penelitian. Mahasiswa yang dinyatakan lulus pada sidang skripsi berhak atas gelar kesarjanaannya. Ujian sidang akhir dilaksanakan secara tertutup. Sistem Penunjang keputusan ujian akhir dengan metode GAP/Profil Matching dengan aplikasi yang berbasis multi user untuk membantu kelulusan ujian akhir mahasiswa UNISKA khususnya mahasiswa jurusan sistem informasi teknik informatika.

\section{HASIL DAN PEMBAHASAN}

\section{Analisa Permasalahan}

Dengan adanya kemajuan teknologi yang sangat pesat, siapapun dapat dengan mudah memperoleh sebuah informasi dari berbagai sumber, termasuk melalui media online. Dikarenakan besarnya kebutuhan akan informasi, saat ini banyak official site di bidang perdagangan, kelembagaan maupun di bidang pendidikan, dalam bidang pendidikan, banyak official site yang memberikan informasi seputar lembaga pendidikan yang dapat di akses oleh public. PESSTA+ merupakan salah satu official site online yang dimiliki oleh Perguruan Tinggi Raharja yang dapat memberikan informasi seputar validasi jurnal dan hibah mahasiswa kapanpun dan di manapun . Pada sistem penilaian penguji yang berjalan di Perguruan Tinggi Raharja masih menggunakan sistem semi manual yang masih memiliki kekurangan yang perlu di analisa dan dikembangkan menjadi sistem yang lebih bermanfaat bagi penguji sidang . 


\section{Use Case Diagram Sistem Yang Berjalan}

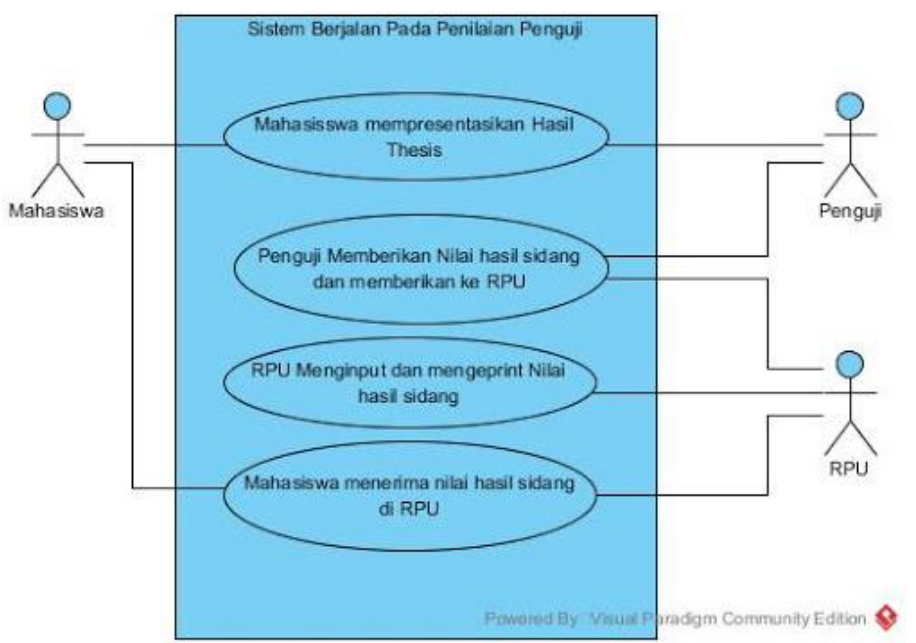

Gambar 1. Use Case Diagram Alur yang Berjalan

Berdasarkan pada gambar Use Case Diagram yang ada diatas, Dapat dijabarkan secara berikut Mahasiswa mempresentasikan hasil karya ilmiah dan terdapat 3 (Tiga) Actor yaitu Mahasiswa dan Penguji setelah mahasiswa selesai presentasi dan tanya jawab Penguji memberikan mahasiswa nilai sidang setelah selesai memberikan nilai Penguji memberi hasil nilai ke RPU dan RPU menginput nilai setelah itu Mahasiswa mengambil hasil penilaian sidang ke RPU .

\section{Pemecahan Masalah}

Setelah mengamati dan meneliti dari permasalahan terdapat beberapa alternatif pemecahan masalah yaitu dengan membuat sistem penilaian penguji di PESSTA+ untuk memudahkan penguji sidang maupun civitas akademik untuk memperoleh informasi yang berkaitan dengan sistem PESSTA+ dan mampu mendapatkan informasi lebih efektif dan efisien ini memungkinkan untuk mempermudah proses penilaian sidang bagi civitas Perguruan Tinggi Raharja .

Guna menyelesaikan permasalahan yang ada diatas, maka terdapat pemecahan masalah yaitu maka diperlukannya sebuah sistem yang memudahkan Penguji untuk menginput Penilaian Penguji dan mendapatkan informasi seputar Penilaian Penguji yang dapat diakses dimanapun dan kapan pun secara online lebih efektif dan efisien .

\section{Listing Program}

Listing Program berikut adalah proses login Penilaian Penguji dengan menggunakan jaringan agar dapat mengakses sumber daya dalam jaringan hanya dengan menggunakan satu akun pengguna saja. pengguna hanya cukup melakukan proses auntentikasi sekali saja untuk mendapatkan izin akses terhadap layanan yang disediakan di dalam jaringan.

Berikut Adalah Contoh Code dari Program Penilaian Penguji : 


$$
<?
$$$$
\text { \$this->title }=\text { 'PESSTA }+\mid \text { Penilaian Sidang Tesis Akhir Plus'; }
$$$$
\text { use yiilhelpers } \backslash \mathrm{Html} \text {; }
$$$$
\text { echo \$client; }
$$$$
\text { ?> }
$$$$
<\text { section class="content" > }
$$$$
\langle\text { div class="box box-success" }>
$$$$
<\text { div class="box-header with-border" }>
$$$$
\langle\text { h3 class="box-title" }><\text { i class="fa fa-users" }>\langle/ \text { i }>\text { Pilih Mahasiswa Tesis }</ h 3\rangle
$$$$
</ \text { div }>
$$

Tahun Ajar \&nbsp;

$<$ ?php echo Yii::\$app->PembC->TahunAjarAktif() ?>

$<$ div class="box-body table-responsive" $>$

<table class="table table-bordered table-striped table-hover">

<tr style="background-color: \#328399; color: \#fff;">

$\langle\mathrm{td}\rangle\langle\mathrm{b}\rangle \mathrm{No}</ \mathrm{td}\rangle$

$<\mathrm{td}>\langle\mathrm{b}>$ No Sidang $</ \mathrm{td}>$

$<$ td $><$ b $>$ Hari, Tanggal $</$ td $>$

$\langle$ td $>\langle$ b $>$ Waktu $</$ td $>$

$\langle\mathrm{td}\rangle\langle\mathrm{b}\rangle$ Ruang $\langle/ \mathrm{td}\rangle$

$\langle\mathrm{td}\rangle\langle\mathrm{b}\rangle \mathrm{NIM}</ \mathrm{td}\rangle$

$\langle\mathrm{td}\rangle\langle\mathrm{b}>$ Mahasiswa $</ \mathrm{td}\rangle$

$\langle\mathrm{td}\rangle\langle\mathrm{b}\rangle$ Posisi $</ \mathrm{td}\rangle$

$\langle$ td $\rangle\langle$ b $>$ Status $</$ td $\rangle$

$</ \operatorname{tr}>$

$<$ ?php

$\$$ no $=1 ;$

foreach (Yii::\$app->PembC->pemb_tampilmahasiswa() as \$data) \{

?>

$\langle\operatorname{tr}\rangle$

$<\mathrm{td}><$ ?php echo \$no; ? $></ \mathrm{td}>$

$<\mathrm{td}\rangle<$ ?php echo \$data['No_Sidang'] ? $></ \mathrm{td}\rangle$

$<\mathrm{td}><$ ?php echo \$data['Hari'] ?>, <?php echo \$data['Tanggal'] ?>-<?php echo \$data['Bulan']

? >-<?php echo \$data['Tahun'] ? $></$ td $>$

$<\mathrm{td}\rangle<$ ?php echo \$data['Waktu'] ? $></$ td $>$

$\langle\mathrm{td}\rangle<$ ?php echo \$data['Ruang'] ? $></ \mathrm{td}\rangle$

$<\mathrm{td}><$ ?php echo \$data['Nim'] ? $></ \mathrm{td}>$

$<\mathrm{td}><$ ?php echo \$data['Nama'] ? $></ \mathrm{td}>$

$<$ ?

if (\$data['Penguji1']==Yii::\$app->PembC->getUsername ()$)\{$

\$hasil1 = "<a

href='http://andhara.raharja.info/fina/web/index.php/input/penguji1?X=".\$data['Nim']."'>";

\$posisi = "Penguji 1";

$\$ \mathrm{x}=$ 'Status1';

\} 
if (\$data['Penguji2']==Yii::\$app->PembC->getUsername( $)$ ) \{

\$hasil $1="<\mathrm{a}$

href='http://andhara.raharja.info/fina/web/index.php/input/kalimatpembukaan?G=".\$data['Nim' ]."'>";

\$posisi = "Penguji 2";

$\$ \mathrm{x}=$ 'Status2';

\}

if (\$data['KetuaPenguji']==Yii::\$app->PembC->getUsername( $)$ ) \{

\$hasil1 = "<a

href='http://andhara.raharja.info/fina/web/index.php/input/kalimatpembuka?Z=".\$data['Nim']." '>";

\$posisi = "Ketua Penguji";

$\$ \mathrm{x}=$ 'Status';

\}

if $(\$ \operatorname{data}[\$ \mathrm{x}]==1)\{$

\$status = "<i class='fa fa-check-square' style='font-size:20px;color:green' $></ \mathrm{i}\rangle "$;

\$hasil2 = "";

\$posisi2 = "Sudah Input Nilai";

\}

else \{

\$status = "<i class='fa fa-minus-square' style='font-size:20px; color:red' $></ \mathrm{i}\rangle$ ";

\$hasil2 = \$hasil1;

$\$$ posisi2 = $\$$ posisi;

\}

?>

$<\mathrm{td}><$ ? echo \$hasil2; echo \$posisi2;?></td $>$

$<\mathrm{td}><$ ? echo \$status;?>

Gambar 2. Script Tampilan input

Gambar 2 merupakan listing program untuk tampilan halaman input pada Penilaian Penguji yang terdapat pada sistem PESSTA+. 


\section{PDESSTA+

Gambar 3. Tampilan awal website PESSTA+ http://pesstaplus.raharja.ac.id/web/site/login

Gambar 3 merupakan tampilan halaman awal pada website PESSTA+ yang di miliki oleh Perguruan Tinggi Raharja yang dapat memberikan informasi seputar penilaian objektif, viewboard, pengertian PESSTA+ dan konsep desain yang dapat di akses secara online dimana pun dan kapan pun. Karna pada sistem penilaian penguji yang berjalan di Perguruan Tinggi Raharja masih menggunakan sistem semi manual akan di terapkannya penilaian penguji di PESSTA+ agar dapat di akses secara online . Maka dari itu dibuatlah sistem dan fitur mengenai sistem penilaian Penguji pada PESSTA+ .

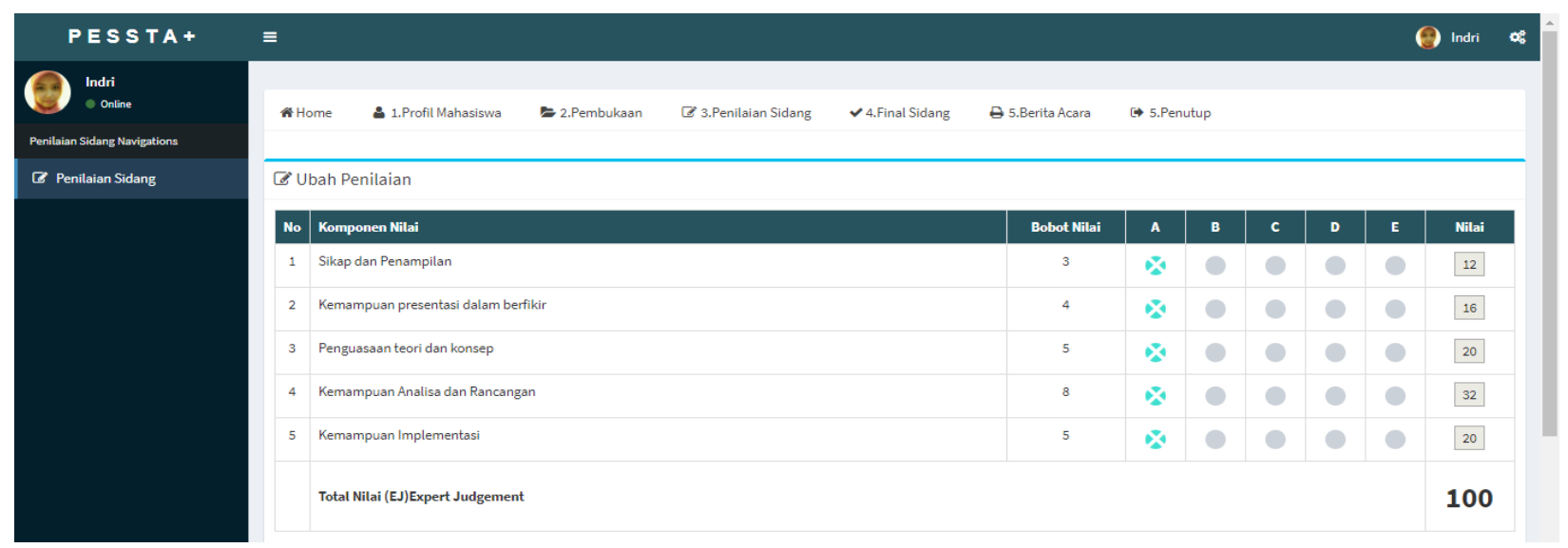

Gambar 4. Tampilan Form Penilaian Penguji

Gambar 4 merupakan tampilan untuk form Penilaian Penguji Pascasarjana dimana penilaian ini sama dengan komponen penilaian mahasiswa sidang tesis. Terdapat 5 komponen yaitu sikap dan tampilan, kemampuan presentasi dalam berfikir, Penguasaan teori dan konsep, 
kemampuan analisa dan rancangan, dan kemampuan Implementasi yang masing-masing komponen memiliki jumlah nilai yang berbeda .

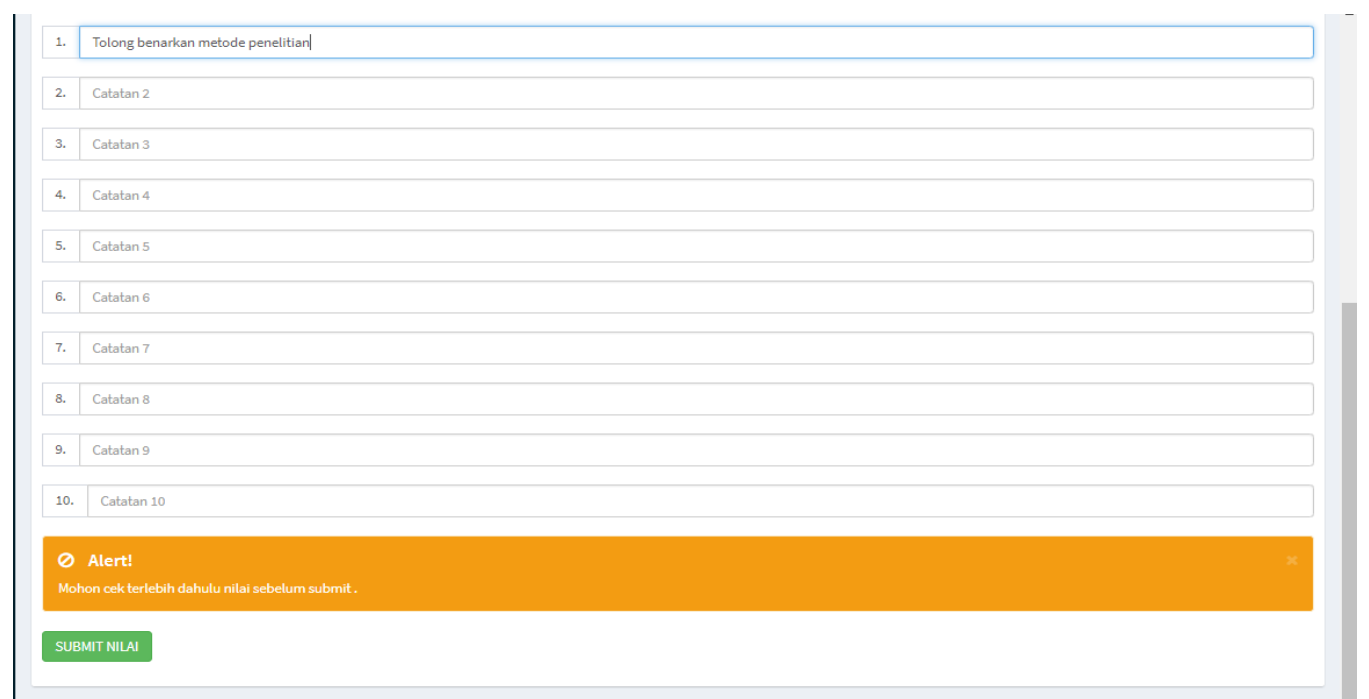

Gambar 5. Tampilan Form Revisi

Gambar 5 merupakan tampilan form Revisi terdapat 10 baris catatan penguji yang dapat mencatat revisi mahasiswa yang sedang di sidang jika mahasiswa terdapat kekurangan dalam penulisan laporan tesis atau project sistem yang di buat .

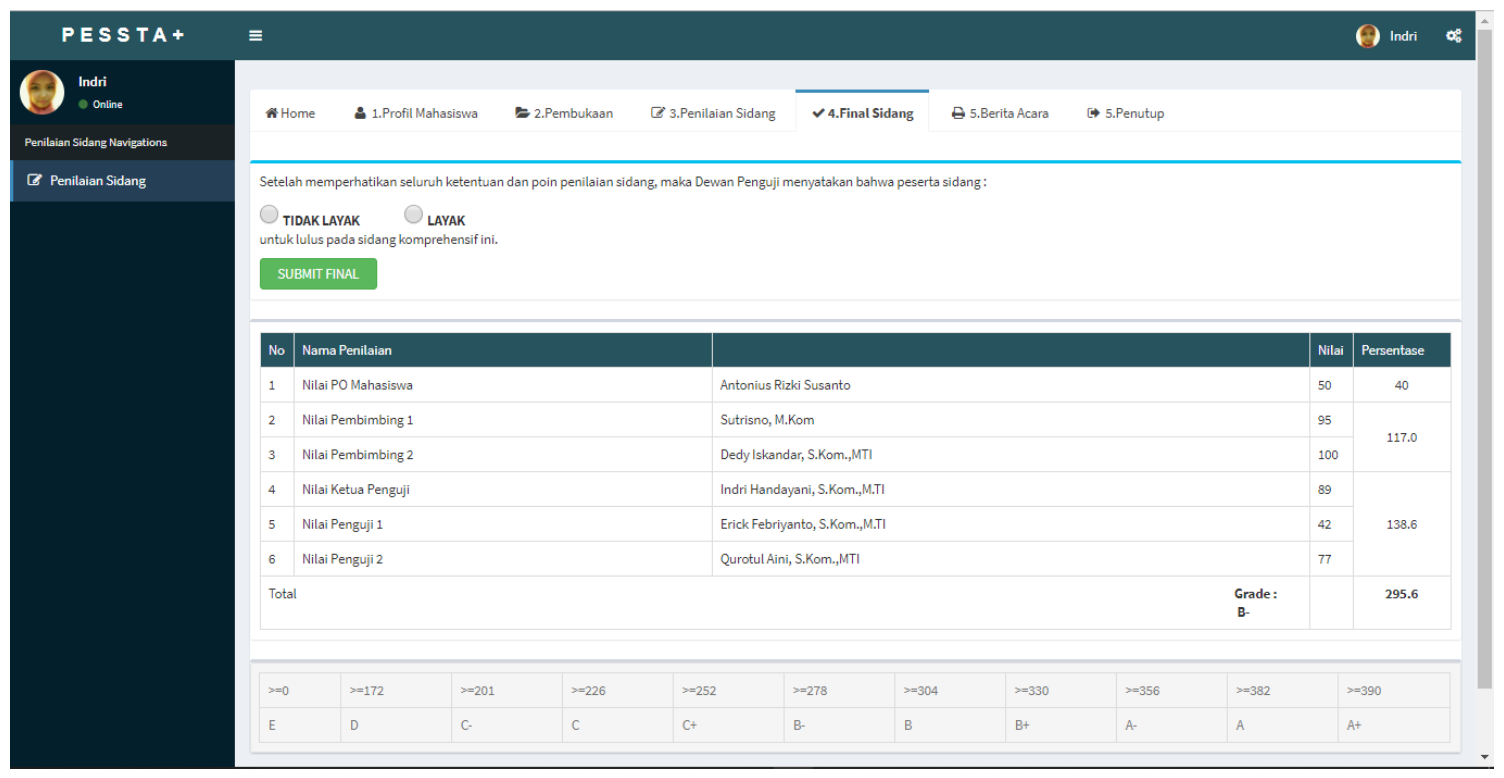

Gambar 6. Tampilan Penilaian Penguji

Gambar diatas tampilan seluruh dewan penguji sudah melakukan penilaian sidang selanjutnya tugas ketua untuk memfinalisasi sidang tersebut untuk mengakhirinya. Apabila proses sidang sudah dilakukan finalisasi yang menandakan bahwa sidang sudah selesai dan tidak 
dapat dilakukan perubahan terhadap nilai tersebut. Proses finalisasi adalah penentuan apakah mahasiswa tersebut layak atau tidak layak .

\section{KESIMPULAN}

Berdasarkan analisa yang telah dilakukan dan telah sesuai dengan apa yang ingin ditampilkan, dapat diambil kesimpulan yaitu dengan adanya sistem Penilaian Sidang S2 pada PESSTA+ sangat memudahkan penguji sidang dalam melakukan penilaian sidang. Dimana sistem dapat di akses dimanapun dan kapanpun secara online. Sangat memudahkan Penguji hanya perlu mengakses website PESSTA+ login Rinfo dan memilih Penilaian Penguji .

\section{DAFTAR PUSTAKA}

[1] Suastra, I. W., \& Ristiati, N. P. (2016). PERMASALAHAN GURU DALAM MERANCANG DAN MENGIMPLEMENTASIKAN PENILAIAN OTENTIK DALAM PEMBELAJARAN SAINS DI SMP DAN SMA. Proceeding SENARI, 4.

[2] Mahfud, M. (2016). Tinjauan hukum Islam terhadap praktek arisan sistem iuran berkembang (studi kasus di Desa Mrisen Kec. Wonosalam Kab. Demak) (Doctoral dissertation, UIN Walisongo).

[3] Handayani, I., Aini, Q., \& Oktaviani, F. (2016). PENERAPAN SISTEM VALIDASI JURNAL DI PESSTA+ SEBAGAI PENILAIAN ARTIKEL ILMIAH DALAM MENDUKUNG KEGIATAN CIVITAS AKADEMIKA. CSRID (Computer Science Research and Its Development Journal), 8(3), 177-190.

[4] Handayani, I., Febriyanto, E., \& Solichin, K. R. P. (2018). Penerapan Viewboard Sebagai Media Informasi Sidang Skripsi Pada PESSTA+ di Perguruan Tinggi. Technomedia Journal,2(2), 52-62.

[5] Farozi, M., Suyanto, M., \& Lutfi, E. T. (2015). Perancangan Sistem Informasi Penilaian Kinerja Sumber Daya Manusia Menggunakan Metode Gamifikasi. Jurnal Teknologi Informasi Respati, 10(30).

[6] Handayani, I., Febriyanto, E., \& Bachri, E. W. (2018). Aplikasi Stat Counter Sebagai Alat Monitoring Aktivitas Website PESSTA+ Pada Perguruan Tinggi Raharja. SISFOTENIKA, 8(2), 188-197.

[7] Saefudin, S., \& Lestari, S. (2017). Sistem Pendukung Keputusan Untuk Penilaian Kinerja Karyawan PT. Mulya Spindo Mills Menggunakan Metode Algoritma C4. 5. ProTekInfo (Pengembangan Riset dan Observasi Teknik Informatika), 2, 40-43.

[8] Sari, D. R., Windarto, A. P., Hartama, D., \& Solikhun, S. (2018). Sistem Pendukung Keputusan untuk Rekomendasi Kelulusan Sidang Skripsi Menggunakan Metode AHPTOPSIS. Jurnal Teknologi dan Sistem Komputer, 6(1).

[9] Prabaningrum, N. (2018). SISTEM INFORMASI SIDANG TUGAS AKHIR DAN PENDAFTARAN YUDISIUM BERBASIS WEB PROGRAM STUDI KOMSI SV UGM (Doctoral dissertation, Universitas Gadjah Mada).

[10] Raharjo, M. R. (2016). Sistem Pendukung Keputusan Kelulusan Ujian Akhir dengan Metode GAP/Profile Matching pada Fakultas Teknologi Informasi UNISKA MAAB. Technologia: Jurnal Ilmiah, 7(4). 